\title{
INTERVENCION ESTATAL Y DESARROLLO EN AMÉRICA LATINA
}

\author{
A. E. Fernández Jilberto \\ (Instituto de Estudios Internacionales \\ de la Universidad de Amsterdam)
}

Diversas razones justifican la revalorización de los estudios sobre el tol del Estado en el desarrollo de América Latina. Entre ellas es posible distinguir dos fundamentales que derivan de procesos políticos recientes. La primera se relaciona con la democratización política de países que habían sido sometidos a prolongados procesos de autoritarismo estatal. La dificultact mayor de estas nuevas democracias (Brasil, Argentina y Uruguay) se ha vinculado a la persistencia de las transformaciones estructurales implementadas por las políticas monetaristas de los Estados autoritarios. En algunos casos, ello condujo al mantenimiento de la política económica precedente. La legitimidad política que la democracia otorga al monetarismo no sólo proviene del reconocimiento de un cierto grado de irreversibilidad de las transformaciones económicas implementadas por las dictaduras militares. También se explica por la participación activa que han tenido en la democratización sectores políticos y sociales que originalmente apoyaron el establecimiento de los regímenes autoritarios.

La segunda razón se hace evidente a partir de las rebeliones militares tecientes en contra del régimen del presidente Alfonsín en Argentina. Ello pone de manifiesto el hecho de que la democracia ha sido conceptualizada. como la sustitución del régimen político autoritario y no como la reformulación-erradicación del tipo de Estado que hizo posible la presencia de dictaduras militares de corte monetarista. Dicha reformulación es indispensable para garantizar la neutralidad política de la butocracia militar sobre el Es- 
tado y favorecer el protagonismo económico de éste en el desarrollo nacional.

En este contexto, en el presente artículo intentamos diseñar cinco pro" blemas vinculados a la relación entre Estado y desarrollo en América Latina. El primero de ellos hace referencia a la intervención permanente del Estado en los procesos económicos. Ello es válido tanto para las políticas económicas de tipo intervencionista como para las políticas antiestatistas, como lo fue el caso de los experimentos monetaristas recientes. El segundo se refiere al debate teórico-político sobre el carácter de los Estados burocráticos autoritarios que tuvo lugar en las oposiciones políticas. El tercero se relaciona con el lugar del estudio sobre el Estado en la sociología política del desarrollo. El cuarto hace teferencia a las relaciones que se establecen entre Estado, régimen político y desarrollo. A partir de dichas relaciones, se intenta conceptualizar la forma de confrontación del Estado con los movimientos sociales y los mecanismos de regulación que éste establece. El quinto problema se vincula a un intento de sistematización de los mecanismos de intervención del Estado en los procesos de reindustrialización de las economías subdesarrolladas sometidas a las transformaciones monetaristas. Finalmente, presentamos las conclusiones a partir del tol futuro del Estado en los procesos de redemocratización.

El supuesto teórico que utilizamos para hacer posible este estudio es el de las formas de Estado vinculadas a los patrones de desartollo que han tenido lugar en América Latina desde la crisis internacional de los años treinta. Por otra parte, hemos dejado de lado toda referencia a los debates europeos y latinoamericanos, teferidos tanto a las teorías del Estado en sociedades avanzadas como a las de los capitalismos dependientes. Es evidente, además, que es difícil formular una teoría del Estado en los países de América Latina sin una referencia necesaria a las teorías del subdesarrollo capitalista. Sin embatgo, ello dificultaría los problemas que en esta oportunidad deseamos enfatizar.

\section{ESTADO E INTERVENCION}

La intervención del Estado ha sido inherente al desarrollo de América Latina. Ello se ha verif́cado tanto en la sustitución del Estado oligárquico por el Estado populista en la década de los treinta como en los intentos de reestructuración monetarista de la economía que implementan los Estados autoritarios en los años setenta. Los Estados buroctáticos autoritarios interpretaban el estancamiento de la industrialización como el resultado de 
1a intervención directa del Estado en la gestión económica. Ello habría derivado en una estatización global de la economía, en la cual la empresa pública marginalizaba la iniciativa privada. ${ }^{1}$

El capitalismo de Estado resultante de la industrialización sustitutiva de importaciones era interpretado como la causa estructural de las distorsiones en el funcionamiento del mercado interno, amparado por la existencia de políticas proteccionistas. Por otra parte, la relación entre industrialización y democtacia, fundamentada en un pacto social por el desarrollo y expresada en la existencia del Estado populista, era considerada como el factor político decisivo en el estancamiento económico.

El sistema democrático creaba un espacio legítimo para las demandas económicas de los actores sociales, que son consideradas negativas para el proceso de acumulación de capital. La democracia era presentada como in. compatible con las exigencias del desarrollo y el crecimiento económico. A ello se sumaba la radicalización política del populismo, que se traducía en la influencia progresiva de una demanda política de tipo socialista. Esto último comprometía no sólo la estabilidad política del Estado populista sometido al cerco político del movimiento de masas, sino que también ponía en peligro la legitinidad del sistema capitalista.

En este contexto, los regímenes autoritarios intentan revertir desde el Estado cuarenta años de desarrollo basados en la industrialización, apoyada por un proceso nacional de acumulación de capital. Para ello se fundamentaron en un intento de remodelación global de la sociedad: sustitución de la forma de Estado, del patrón de desarrollo y de la forma de inserción de la economía en el sistema mundial. La materialización de dicha remodelación es lo que se designó como pattón de desarrollo asociado, ${ }^{3}$ la cual se expresó en dos variantes: la de la profundización de la industrialización

1. Joseph Ramos, Neoconservative Economics in the Soutber Cone of Latin America, John Hopkins University Press, London, 1986. Alejandro Foxley, Latin American Experiments in Neoconservative Economic, University of California Press, Berkeiey, 1983. Stephen D. Krasner, Structural Conflict. The Tbird World Againts Global Liberalism, University of California Press, Berkeley, 1985. Humberto Vega y Jaime RuizTagle, Capitalismo Autoritario y Desarrollo Económico: Chile 1973-1981, Academia de Humanismo Cristiano, Programa de Economía del Trabajo, Chite, 1983. Alain Lipietz, How Monetarism has Choked Tbird Korld Industrialization, N.L.R. 145, mayojunio, EE UU, 1984.

2. A. E. Fernández Jilberto, Dictadura militar y oposición politica en Chile 1973-1981, Latin America Studies 31, CEDLA/Foris, Amsterdam, 1985. Pilar Vergara, Auge y caida del neoliberalismo en Cbile, FLACSO, Chile, 1984.

3. F. F. Cardoso, Estado y sociedad en América Latina, Ediciones Nueva Visión, Buenos Aires, 1972. Luiz Bresser Pereira, Development and Crisis in Brazil 19301983, Westview Press, Colorado, 1984. F. H. Cardoso y Enzo Faletto, Dependency and Development in Latin America, University of Catifornia Press, Berkeley, 1979.

11. 
sobre la base del capital internacional (caso de Brasil) y la de la reprimarización de la economía (casos de Argentina, Chile y Uruguay). El instrumento esencial utilizado para dicho objetivo fueron los mecanismos de privatización general de la economía, la reestructuración del funcionamiento del mercado como determinante exclusivo en la asignación de los recursos del sistema económico, la apertura irrestricta de la economía al mercado mundial, y la estatización política de la sociedad civil. Esto condujo a tana reformulación global de las relaciones sociales y a una alteración significativa de la participación de las clases sociales en el proceso económico. La marginación progresiva de los sectores industriales ligados al mercado in* terno condujo a una acentuada desindustrialización de la economía (Chile, Argentina). Su rol político en el modelo de desartollo precedente intentó ser sustituido por la formación de una burguesía financiera, ${ }^{4}$ que apoyaba su existencia en el endeudamiento internacional.

EI protagonismo político de los nuevos sectores financieros se afianzaría en el desarrollo de una nueva tecnocracia empresarial, resultante de la transferencia al mercado de las funciones económicas precedentes del Estado. Ella constituiría una élite de gran calificación y altamente ideologizada, que apoyaría desde el área privada de la economía la materialización del esquema global de reestructuración impuesto por las burocracias militares. Las dictaduras militares deberían haber conducido al establecimiento de un régimen político de «democracia protegida» que garantizata la reproducción de la dimensión autoritaria del Estado, a fin de conservar las transformaciones económicas implementadas por las políticas monetaristas.

La democratización relativamente reciente de algunos países de Amé. rica Latina (Bolivia, Argentina, Brasil y Uruguay) abrió el debate sobre el grado de reversibilidad de las transformaciones estructurales sufridas por las economías sometidas a los Estados burocxáticos autoritatios. Por otra parte, tanto los efectos de la deuda externa como los de la crisis internacional han conducido a la tevalorización de la política de industrialización sustitutiva de importaciones. Esto último ha replanteado el interrogante sobre el carácter que debe asumir la intervención del Estado.

4. Ricardo Lagos, «Le secteur emergent de la bourgeoisie», Revue Amerique Latine núm, 6, Cetrail, París, 1981. Alexander Schubert, Die Internationale Verschuldung. Die Dritte Welt und das Transnationale Bankensysteeem, Suhrkamp, Frankfurt, 1985. E. C. L. A., External Debt in Latin America. Adjustment Policies and Renegotiation, Rienner Publisher, Colorado, 1985. Jonathan Hakim, Latin America's Financial Crisis: Causes and Cures. In Latin America and the World Recession, editado por Esperanza Durán, Cambridge University Press, 1985. 


\section{EL DEBATE SOBRE EL CARACTER DE LOS ESTADOS AUTORITARIOS}

Si se observa retrospectivamente el debate respecto a la forma de Estado representada por las dictaduras militares y las causas que gestaton su presencia, es posible establecer la existencia de dos tendencias. La primera es de tipo culturalista y sugiere la existencia de un tipo de relación particular entre el poder, las instituciones militares y la sociedad civil propia del «mundo íbérico». El intento por establecer un «modelo corporativo», «neofalangista», sería expresivo de ese tipo de relación particular. Las frecuentes intervenciones militares en los Estados latinoameticanos sería el tesultado de la existencia de "residuos culturales de las guerras civiles del siglo XIX». La desaparición del Estado colonial habría liberado las fuerzas anarquistas y centrífugas diz sos caudillos, descentralizando el uso de la violencia. Sólo en el curso de los años cincuenta y como resultado de la populatidad de las teorías de la modernización se establece una relación explicativa entre las dictaduras militares y el problema del desarrollo. ${ }^{6}$ Si bien en esta nueva perspectiva los mecanismos de funcionamiento del poder militar son ignorados, existe un conocimiento sistemático de las formas operativas del subdesarrollo: ${ }^{7}$ sistema centro-periferia, deterioto de los términos de intercambio, dualismo estructural, etc. Tanto la popularidad de las teotías de la modernización cono la relación explicativa que se establece entre intervención militar y subdesarrollo conducitían al «redescubrimiento» del rol protagonista del Estado en las sociedades latinoamericanas. ${ }^{8}$ Se reconoce no sólo su importancia esencial en la constitución del "Capitalismo de Estado» a que da curso el esquema de desarrollo industrial sustitutivo de importaciones, sino también su capacidad para generar clases sociales funcionales a los esquemas económicos aplicados.

La segunda tendencia surge en el curso de los años setenta. No es

5. Cecil Jane, Liberty and Despotism in Spanisb America, New York, 1966. Howard Wiarda, Towatd a Framework for the Study of Political Cbange in the IbericLatin Tradition: The Corporative Model, World Politics, 1973.

6. Alain Rouquie, L'Etat Militaire en Amérique Latine, Seuil, París, 1982.

7. Raúl Prebisch, El desarrollo econbmico de América Latina y algunos de sus principales problemas, Santiago de Chile, 1949.

8. Octavio Ianni, La formación del Estado populista en América Latina, Serie Popular Era, México, 1975. Gítberto Mathias y Pierre Salama, L'État sousdeveloppé. Des metropoles at Tiers Monde, Maspéro, París, 1983. Nora Hamilton, Tbe Limits of State Autonomy. Post-Revolutionary Aféxico, Princeton University Press, 1982. Gino Germani, Autboritarianism, Facism and National Populism, Transaction Book, New Bruswick, New Jersey, 1978. Alfred Stepan, The State and Society. Peru in Comparative Perspective, Princeton Universitw Dress, 1979. 
sólo el resultado del impacto político causado por la presencia de las «nuevas dictaduras», sino que también juega un rol significativo la consolidación teórica del debate sobre «las situaciones de dependencia», que había sido iniciado en el curso de los años sesenta y principio de los setenta. ${ }^{9}$ En esta perspectiva, el debate sobre las teorías de la dependencia debe ser considerado como un proceso de recuperación de la autonomía teórica del marxismo latinoamericano y como un rechazo definitivo al marxismo de los partidos comunistas, que formulaban una versión politizada del dualismo estructural ${ }^{10}$ y el deterioro de los términos de intercambio contenidos en las versiones latinoamericanas de las teorías de la modernización. " Elio no era sólo el resultado de la influencia política de la Revolución cubana, expresaba también la relevancia teórica de los intelectuales brasileños que participaban en dicho debate y que tenían como objeto de referencia la dictadura militar establecida en Brasil (1964).

En esta interpretación se enfatiza, pot una parte, la relación existente entre el surgimiento de los Estados autoritarios y las ctisis del proceso de industrialización; y, por otra, las exigencias provenientes de la unueva división internacional del trabajo». La reestructuración del capitalismo dependiente es considerada como el resultado lógico de la implementación de nuevos mecanismos de acumulación de capital. Ello deriva en una conceptualización «instrumentalista», que explica la presencia de las dictaduras militares como el resultado de las exigencias del capitalismo mundial y de la «necesidad» del desarrollo nacional por imponer un Estado fuerte que garantice la sepresión de los movimientos sociales, las inversiones de capital y acelere el proceso de acumulación. Sin embargo, existe una variante que puso más énfasis en la interpretación del autoritarismo estatal como fenómeno sociológico político. Al mismo tiempo se concentró preponderantemente en la interpretación de la forma de Estado representada por las dic-

9. A. E. Fernández Jilberto, El anälisis de situaciones de dependencia y la reestructuración del capitalismo dependiente (Apuntes para una bistoria conceptual del estudio del capitalismo dependiente en América Latina), a Journal of Latin American and caribbean Studies. Amsterdam, 1984.

10. Carlos Ominami, «Critique des theories du developpment en Ametique La. tine», Revue Tiers Monde, tomo XX, núm. 80, París, 1979. Boris Goldemberg, Kommunismus in Lateinamerika, Verlag Kohthammer, Stuttgart, 1971. Babakar Sine, Imperialisme et théories sociologiques du developpement, Editions Antbropos, París, 1975.

11. A. E. Fernández Jitberto, «El Marxismo de las sociedades dependientes (Apuntes para una discusión actual referida a la legitimidad del marxismo en las sociedades de capitalismo autoritario)', Revista Sistema, núms. 60-61, Madrid, España, 1984. Otto Holman en Henk Overbeek, Immanuel Wallerstein en het Einde van het Kapitalistne, Politieke implikaties van de Wereldsysteem-theorie, Tijdschrift voor Politieke Economie, Amsterdam, junio, 1986. 
taduras y la necesidad política de formular una alternativa democratizadora viable.

En la dirección señalada se formularon cuatro interpretaciones. La primera de ellas caracterizó las dictaduras como Estados buroctáticos autoritarios. Su presencia sería el resultado de una fase de transformaciones significativas en los mecanismos de acumulación de capital, que expresaŕa la necesidad de una "profundización» del desarrollo capitalista dependiente. Ello se verificaría sólo en los países latinoamericanos dotados ya de una extensa industrialización, ${ }^{12}$ es decir, sólo tendría lugar en las economías que lograton el más alto índice de desartollo en el proceso de industrialización sustitutiva de importaciones. La definición específica de esta forma de Estado estaría constituida por el hecho de que representan sistemas de exclusión política y cierran los canales de acceso al Estado, los cuales habían sido utilizados tradicionalmente por los sectores sociales del «populismo». Los mecanismos de exclusión política son acompañados de una radicalización en la marginalidad social y económica. El proceso de exclusión es materializado por mecanismos de despolitización de la sociedad, en donde las desigualdades sociales son consideradas como problemas técnicos y no como resultado de una desigual distribución del poder entre los diferentes sectores sociales que participan de la estrategia de desarrollo. La clase política de dicho Estado desplazaría a la clase media tradicional en beneficio de un nuevo personal preveniente de instituciones altamente burocratizadas, como las fuerzas armadas y las grandes empresas privadas de capital nacio. nal y multinacional.

Una segunda caracterización es la que designó las dictaduras militares como un «Estado de excepción bajo la forma de Estado militar». Sería el resultado de una contrarrevolución burguesa protagonizada por un Estado que corresponde a un tipo general de Estado capitalista y que asume las características de un «Estado de excepción permanente». ${ }^{13} \mathrm{La}$ instautación de esta forma de Estado militar encontraría sus antecedentes causales en la crisis de los «movimientos nacionales populistas» a que condujo el proceso de industrialización y el Estado populista, después de la crisis internacional de los años treinta. De allí deriva su carácter específico en tanto Estado de contrainsurgencia. La tercera interpretación hace referencia a la

12. Guillermo O'Donnell:

- «Reflexiones sobre las tendencias del Estado burocrático autoritario», Revista Mexicana de Sociologia, Vol. XXXIX, núm. 1, México, 1977.

- Estado y alianzas de clases en la Aggentina de 1956-1976. Centro de Estudios de Estado y Socicdad, Buenos Aires, 1977.

13. Tomás Amadeo Vasconi, Gran capital y militarización en América Latina, Serie Popular Era, México, 1978. 
necesidad de formular una teoría de los ciclos del desarrollo del «capitalismo periférico», ausente en la versión original de la teoría latinoamericana de la modernización ${ }^{14} \mathrm{y}$ en el esquema centro-periferia formulado por Raúl Prebisch en la década de los cincuenta. Existirían dos ciclos que se corres. ponden con las exigencias de acumulación de capital y con el fortalecimiento del mercado interno, respectivamente. La permanencia prolongada de políticas de redistribución de ingresos exigidas por la participación democrática de los movimientos populistas conduciría al estancamiento del proceso de acumulación de capital. En este sentido, la constitución de las dictaduras militares tendría como función el restablecimiento de los mecanismos de acumulación de capital, que actuarían regresivamente sobre los salarios. Como resultado de ello, estaríamos en presencia del ciclo autoritario del capitalismo periférico. El ciclo autoritario entraría en crisis a partir de la necesidad de «realización del capital», que conduciría al restablecimiento del rol del mercado interno y del crecimiento de los salarios, reiniciándose el ciclo democrático.

Finalmente, el caracterizar la militarización de los Estados latinoamericanos como «fascismos dependientes» constituyó la forma interptetativa dominante. El primero en utilizar dicha categoría para analizar el tema de la crisis económica de América Latina y su vinculación con las nuevas modalidades de capital fue Theotonio Dos Santos. ${ }^{15}$ La relación entre crisis económica y crisis política era presentada en términos de alternativas políticas como un dilema entre socialismo y fascismo. La base material del «fascismo dependiente» estaría constituida por la creciente penetración del capital internacional en el sector de industrialización sustitutiva, en reemplazo de las inversiones en las actividades primario-exportadoras. La variante más significativa de este tipo de conceptualización del Estado autoritario fue la representada por algunos partidos comunistas de América Latina. Al definir las dictaduras militates como fascistas, utilizan la misma conceptualización formulada por George Dimitrov en el VII Congreso de la III Internacional, en 1935: dictadura terrorista del capital financiero. ${ }^{16}$ El objetivo específico de dicha definición estuvo constituido por el intento de la formulación de una política de Frente Popular como alternativa y estrategia de derrocamiento de la dictadura.

14. Raúl Prebisch, Capitalismo Periférico. Crisis y Transformación, Fondo de Cuitura Económica, México, 1981.

15. Theotonio Dos Santos, Socialismo o Fascismo, Editorial Nueva Imagen, Mexico, 1975.

16. George Dimitrov, L'offensive du Fascisme et les taches de l'Internationale Communiste dans la lutte pour l'unité de la classe ouvriere contra le Fascisme, Rapport au VII Congrès Mondiale de l'Internationale Communiste, 2 agosto de 1935. 


\section{ESTADO Y SOCIOLOGIA POLITICA DEL DESARROLLO}

La telación directa entre Estado y desarrollo sugerida en el conjunto de las interpretaciones señaladas pone de manifiesto el intetrogante teferido al lugar que el estudio del Estado debe ocupar en la sociología política del desarrollo. Hoy parece evidente que cuando en América Latina se hace referencia al estudio del Estado, ello se vincula a la consideración de las formas de Estado (oligátquico, populista, burocrático, autoritario), que se teconocen como el resultado lógico de la existencia de determinados patrones de desarrollo. Estos últimos (primatio exportador, incustrialización sustitutiva, desarrollo asociado) operarian como el fundamento material de las diversas formas de Estado.

Sin embargo, el agente principal del desarrollo no puede estar constituido por un actor ubicado en el sistema de relaciones sociales. No está constituido por una clase social, en la medida en que ellas son agentes del funcionamiento de la sociedad; y, por tanto, no se constituyen en agentes del paso de un tipo de sociedad a otra (paso de la sociedad oligárquica a la sociedad de masas, pot ejemplo). Es esto lo que permite diferenciar la sociología política del desarrollo de una sociología de las estructuras sociales. ${ }^{17}$ Si en la sociología de las estructuras sociales las clases son los actores esenciales, en la sociología política del desarrollo lo es el Estado. El Estado se constituye en el agente principal de la formación de una clase dirigente y en el actor por definición en el paso de un tipo de sociedad a otra, la cual se ubica en un proceso general de reestructuración. Por reestructuración entendemos tanto la sustitución de una forma de Estado como el reemplazo del patrón de desartollo de la forma de inserción de la economía en el sistema internacional y el cambio del sistema de relaciones entre Estado y sociedad civil.

Del hecho de que el Estado se constituya en el agente principal de una clase dirigente se deriva tanto su autonomía como su dependencia de las clases hegemónicas. Autonomía y dependencia son definidas por el grado de constitución de una clase política del Estado, como lo fueron las clases medias que imprimieron un carácter mesocrático al Estado populista, o las burocracias militares transformadas en clase política de los Estados burocráticos autoritarios. ${ }^{18}$

17. Alain Touraine, Les sociétés dependantes, Sociologie Nouvelle, Deculot, Paris, $1977_{\text {, }}$

18. Welmoed Koekebakker (en A. E. Fernández Jilberto), «Militairen als Ma. nagers van de Staat. Autoritaire Burocratische Regimes in Indonesie en Latijns Ame. rica», Desde Wereld, Jaargang 5, núm. 3, 1986. 


\section{ESTADO, REGIMEN POLITICO Y DESARROLLO}

Si el Estado es definido como el punto de condensación de la correlación de fuerzas sociales entre diversas fracciones de clases que constituyen el bloque en el poder, su papel principal estará determinado por la necesidad de garantizar la continuidad o sustitución de un patrón de desattollo. Ésta fue la función del Estado oligárquico tespecto de la economía primario-exportadora o del Estado populista respecto de la industrialización sustitutiva de importaciones. También lo fue respecto de la sustitución del Estado populista por el butocrático autoritario.

El régimen político, en cambio, debe ser definido como el lugar de ajus. te de la participación de los diversos componentes del bloque en el poder respecto de los beneficios del desatrollo. También se constituye, en el caso del régimen democrático, en el mecanismo de incorporación de otros sectores sociales a dicho beneficio.

Ha sido Helio Jaguaribe ${ }^{19}$ el que mejor ptofundizó en la sistematización de la telación entre régimen político y desarrollo. Para ello establece tres modelos básicos que se fundamentan en el grado de generalización de la participación política de la sociedad civil y en los modelos de movilizacion:

- El Nacional Capitalismo, que expresaría la vinculación entre los sectores progresistas de la burguesía nacional, de la clase media y del proletariado. Ellos se organizarían bajo la dirección «neobismarkiana» de un jefe de Estado apoyado por la formación de un partido nacional del desarrollo. Este partido debería estar en condiciones de obtener una significación electoral suficiente para favorecer el desarrollo de manera consensual.

- El Capitalismo de Estado, que encontraría su base de apoyo en el control del Estado ejercido por la tecnoctacia estatal o por los sectores progresistas de las fuetzas armadas. El ascenso al poder de dichos sectores se verificaría a través de un golpe de Estado que genera la organización de un partido de «Revolución Nacional». Dicho partido tendría como tarea la readecuación del Estado al objetivo de la promoción del desarrollo nacional (serían los casos de Vargas en Brasil, Ibáñez en Chile, Perón en Argentina y Velasco Alvarado en Perú).

- El Socialismo desarrollista, que expresa la conquista del Estado por parte de una élite revolucionatia anticapitalista y prodesarrollista. En la implementación del desarrollo ejecutaría formas socialistas de acumulación

19. Helio Jaguaribe, Brasil: Crise e Alternativas, Zahar Editores, Río de Janeiro, 1974. 
de capital y de gestión económica, afianzada en una estrategia de movilización social dirigida por la existencia de un partido revolucionario.

Un segundo intento por establecer una telación sistemática entre régimen político y desartollo es el que se fundamenta en las formas de control del proceso de acumulación de capital. ${ }^{20}$ Se establece la existencia de diversas formas de control sobre dicho proceso:

- Control público del proceso de acumulación (Cuba y Nicaragua), que tiene lugar en sociedades en las cuales el sistema económico se apoya predominantemente en las empresas públicas.

- Control de libre empresa sobre el proceso de acumulación de capital (Colombia), en el cual la empresa pública juega un rol subsidiario a la lógica de acumulación privada.

- Control compartido del proceso de acumulación, en el cual se establece una diferenciación de áreas eçonómicas repartidas entre empresas públicas y privadas, reguladas por diversas formas de intervención del Estado (Venezuela, México, Brasil). ${ }^{21}$ Estas diversas formas de control combinarían diferentes regímenes políticos: democracias tepresentativas, regimenes de autocracia burocrática de carácter civil o militar y dictaduras populistas.

Existe un tercer intento de explicación de las relaciones entre régimen político y desarrollo, que se fundamenta en los trabajos de Aglietta. ${ }^{22}$ Éste se basa en la aplicación de los conceptos de régimen de acumulación y modo de tegulación de la economía. Aun cuando originalmente dichos conceptos estaban destinados a reabrir el debate europeo sobre los fundamentos teóricos del capitalismo monopolista de Estado, fueron introducidos en el análisis del desarrollo latinoamericano por los estudios de Carlos Ominami y Alain Lipietz. ${ }^{23}$

20. F. H. Cardoso, Estado y Sociedad en Amb́rica Latina, Ediciones Nueva Visión, Buenos Aires, 1972.

21. Sobre este tema se pueden consultar los siguientes trabajos:

- Arturo Bronstein, Las relaciones laborales en las empresas estatales de América Latina. Oficina Internacional del Trabajo (OIT), Ginebra, 1981.

- Janet Keily de Escobar, Empresas del Estado en América Latina, Ediciones IESA, Caracas, 1985.

22. Michel Aglietta, Regulación y crisis del capitalismo, Siglo XXI editores, Mé. xico, 1979 .

23. Carlos Ominami, Le Tiers Monde dans la crise, Editions La Découverte, Patís, 1986. Alain Lipietz, Mirages et miracles. Problemes de l'industrialisation dans le Tiers Monde, Editions La Découverte, Paris, 1986. 
La introducción de los conceptos de régimen de acumulación y modos de regulación es considerada necesaria en la medida en que permitían superat la dicotomía centro-periferia en el análisis del sistema mundial. Dicha dicotomía había impedido conceptualizar la diversidad de formas de acumulación e integración internacional que tenía lugar en las economías subdesarrolladas. Ello era el tesultado del hecho de que tanto el debate sobre el intercambio desigual ${ }^{24}$ como el de la dependencia ${ }^{25}$ suponían la existencia de una homogeneización de los procesos de acumulación dependiente que tenían lugar en los países de la periferia.

Ominami intenta diseñar, a partir de la diversidad de formas de acumulación, una tipología de la inserción de las economías subdesarrolladas en el mercado mundial. Se fundamenta en la intensidad de la utilización y combinación de tres estrategias de desarrollo: promoción de exportaciones, sustitución de importaciones y sustitución de exportaciones. De ello resulta la existencia de cinco formas de acumulación dependiente: economías preindustriales, economías de régimen rentista, economías de industrialización extravertida, economías taylorianas y economías de régimen mixto. La estabilidad de estos regímenes de acumulación dependerf́a de la capacidad del régimen político constituido en mecanismo de regulación de dichos regímenes. En esta dirección el Estado constituiría la garantía estructural de toda forma de regulación.

El desarrollo de estos conceptos haría posible la introducción del concepto de fordismo periférico, a fin de explicar las crisis que condujeron en América Latina a la sustitución de los Estados populistas por los Estados butocráticos autoritatios. Lo que en las economías eutopeas se designa como fordismo para conceptualizar la fusión entre socialdemocracia y keynesianismo, que constituiría la base del Welfare State, en las sociedades latinoamericanas estaría representado por la vinculación entre el populismo y el keynesianismo verificada en la industrialización sustitutiva apoyada por el Estado populista.

24. Samir Amin, Le developpement inegal. Essai sur les formations sociales du capitalisme péripherique, Ed. de Minuit, Paxís, 1973.

25. F. H. Cardoso y Enzo Faletto, Dependencia y desarrollo en América Latina, Siglo XXI editores, México, 1967. James Petras, «Critical Perspectives on Imperialism and Social Class in The Thitd Worlds, Montbly Review Press, Nueva York y Londres, 1978. 


\section{MECANISMOS ESTAT ALES DE INTERVENCION}

Estudios recientes sobre las funciones económicas y políticas del Estado en los países en desarrollo han intentado identificar los mecanismos de intervención económica. ${ }^{26}$ Dicha identificación permite efectivizar el tol del Estado en la profundización del desartollo industrial. Ello requiere la definición previa de tres tipos de problemasi, de los que dependen los mecanismos de intervención:

- La forma de Estado, que depende de la naturaleza de su clase politica, del tipo de clase dirigente que lo forma, de la correlación de fuerzas y alianzas de clases que constituyen el bloque en el poder y del tipo de industrialización que de ello se deriva. ${ }^{27}$

- La capacidad político-administrativa del Estado, que adquiere tres dimensiones: a) su capacidad política para definir y cohesionar la sociedad en términos de una ideología de la industrialización, como lo fue el caso de populismo en la industrialización sustitutiva. En esta dirección el Estado se constituye en el líder del proceso de desartollo, fortaleciendo su autonomía a partir de la consolidación efectiva de su clase política. ${ }^{28}$ Su intervención en términos de programación del subdesarrollo adquiere una relevancia significativa; $b$ ) eficacia administrativa de sus aparatos institucionales para responder a las políticas industriales que se definen. Ella debería garantizar la penetración de dichas políticas en la totalidad de la estructura económica, eliminando los sectores que tesisten a la industrialización como patrón predominante en el desatrollo; $c$ capacidad técnica de análisis de los problemas generados en la implementación y el desartollo de la industrialización."

- Los modos de participación de las instituciones del Estado en los procesos econónicos y sociales generados por la industrialización.$^{30}$ Ellos

26. David Evans and Parvin Alizadeh, Industriatisation and the Visible Hand. In Third World Industrialisation in the 1980's. Open Economies in a Closing World, editado por Raphael Kaplinsky, Frank Cass, Londres, 1984.

27. D. Benett and K. Sharpe, The State as Banker and Entrepreneur: The Last resort Cbaracter of the Mexican State's Economic Intervention 1917-1976, Comparative Politics, vol. 12, 1982.

28. A. E. Fernández Yíberto, «Burocracia militar, oposición política y transición denoctáticas, Revista CIDOB, núm. 9, Barceiona, 1986. G. Mathias et P. Salama, L'Etat sousdéveloppé. Des metropoles au Tiers Monde, Maspéro, Paris, 1983.

29. M. Stostak, «Le secteur public dans les pays du Tiers Monde: sa formation, son expansions, Revue Tiers Monde, tomo XXIV, París, 1983.

30. Moises Iconicoff, «Theorie et strategie du développement: le rol de I'Etat», Revue Tiers Monde, tomo XXIV, Patís, 1983. 
corresponden a dos tipos: ${ }^{31}$ 1) Las medidas paramétricas, que aseguran una cierta autonomía, tanto para los actores económicos como para los procesos que ellos generan. Se distinguen tres formas paramétricas: $a$ ) las regulativas de los procesos macroeconómicos (tasas de interés, subsidios, tarifas de importaciones, etc.). A través de ellas el Estado se reserva la función de matriz correctiva del funcionamiento del mercado; $b$ ) las institucionales, que buscan conservar un contexto favorable a la industrialización por medio de utilización del sistema financiero, jurídico y legal; c) las infraestructurales, que corresponden a las obras públicas y empresas del Estado destinadas a apoyar subsidiariamente el proceso de industrialización. 2) Medidas de penetración, que representan el intento estatal por ejercer un control más directo sobre las inversiones, producción y mercado. Entre ellas es posible distinguir dos: a) las de tipo administrativo, que corresponden a las organizaciones estatales nacionales, tegionales y locales de control de la producción, inversión y mercado. A través de ellas el Estado busca supervisar la industrialización y actuar correctivamente sobre la empresa privada; b) las políticas, que corresponden a la intervención del Estado sobre la estructura social derivada del proceso económico y actúa como regulador de las desigualdades sociales y económicas.

\section{CONCLUSIONES}

Los procesos de redemocratización reciente que han tenido lugar en algunos países de América Latina han formulado dos problemas esenciales en relación al Estado. El primero de ellos corresponde a la pérdida de soberanía a que han sido confrontados dichos Estados como efecto de la aplicación de esquemas monetaristas de reestructuración económica. La deuda externa y la dependencia que ella establece respecto del Fondo Monetario Internacional imposibilitan la determinación soberana de políticas económicas. Este proceso puede ser asimilado a un fenómeno de "re-compradorización» del Estado. El segundo problema tiene relación con la capacidad política de las nuevas democtacias para renacionalizar el Estado y revertir los efectos estructurales de las transformaciones monetaristas. Paralelamente, las exigencias de cancelación de la deuda externa se han traducido en una reducción significativa de la capacidad de importación de la economía. Ello

31. White Gordon, Developmental States and Socialist Industrialisation in the Tbird World. In Trid World Industrialisation in the 1980s. Open Economies in a Closing World, editado por Raphael Kaplinsky, Frank Cass, Londres, 1984. 
ha obligado a formular un esfuetzo teciente de sustitución de importaciones. Dicho esfuerzo reabre el debate sobre la intervención del Estado, el proteccionismo económico y la reindustrialización de las economías que fueron sometidas a prolongados procesos de: reestructuración monetarista. 